\title{
CONTRATAÇÃO TEMPORÁRIA PELA ADMINISTRAÇÃO PÚBLICA NO ANO ELEITORAL: RESTRIÇÕES IMPOSTAS PELA LEGISLAÇÃO E SUA INTERPRETAÇÃO JURISPRUDENCIAL
}

\author{
Marcus Cléo Garcia
}

Resumo: No intuito de impedir o desequilíbrio na disputa eleitoral decorrente do desvio de finalidade na utilização de bens e recursos pertencentes ao Estado, o legislador fixou inúmeras restrições ao agir dos agentes públicos no ano das eleições, detalhadamente descritas no art. 73 da Lei n. 9.504/1997, as quais, caso desrespeitadas, sujeitam o infrator e os beneficiados pela prática ilícita ao pagamento de multa e, em situações mais graves, à cassação do mandato eletivo. Entre as vedações mais relevantes, está a proibição de "nomear, contratar ou de qualquer forma admitir, demitir sem justa causa, suprimir ou readaptar vantagens ou por outros meios dificultar ou impedir o exercício funcional e, ainda, ex officio, remover, transferir ou exonerar servidor público, na circunscrição do pleito, nos três meses que o antecedem e até a posse dos eleitos, sob pena de nulidade do pleito"3. O fundamento principiológico que constitui a razão de ser de referida vedação e, por conseguinte, o interesse público que busca proteger é, ao fim e ao cabo, preservar a igualdade entre os candidatos em face do uso abusivo do poder político. É preciso ponderar, contudo, que a prestação de serviços públicos de qualidade e de forma contínua, especialmente em áreas sensíveis como a educação, saúde e segurança, também constitui interesse público de semelhante importância. No intuito de compatibilizar esses anseios sociais e evitar a paralisação da atividade administrativa durante o período eleitoral, foram previstas algumas exceções à referida vedação legal, entre as quais a possibilidade de "nomeação ou contratação necessária à instalação ou ao funcionamento inadiável de serviços públicos essenciais, com prévia e expressa autorização do Chefe do Poder Executivo"״ . Embora a permissão prevista pela norma não suscite dúvidas, a interpretação do conceito "serviço público essencial e inadiável" nela inserido tem alimentado relevantes discussões jurisprudenciais. Nesse sentido, os operadores do direito tem tentado, num primeiro momento, indicar quais deveriam ser os serviços públicos considerados essenciais? E se seria impositivo estabelecer alguma diferenciação para fins eleitorais? No segundo momento, o embate de ideias se volta para os elementos configuradores do pressuposto da inadiabilidade da prestação desse tipo de serviço público. Ao se debruçar sobre essas questões, o Tribunal Superior Eleitoral firmou posição jurisprudencial bastante restritiva a respeito da matéria. Impelida a dirimir semelhantes indagações, a Corte Regional Catarinense construiu entendimento diverso, concluindo pela necessidade de emprestar interpretação mais ampla à norma de exceção, especialmente quando considerados os parâmetros estabelecidos pelo legislador constituinte a respeito dos direitos sociais fundamentais. Para melhor elucidar o entrechoque de referidas teses jurisprudenciais, o presente artigo irá expor os fundamentos adotados no Acórdão TRESC n. 33.001, de 7.3.2018, da lavra do Juiz César Augusto Mimoso Ruiz Abreu, para contrapor o posicionamento da Corte Superior Eleitoral.

Palavras-chave: Condutas vedadas. Contratação temporária. Serviço público essencial.

\footnotetext{
${ }^{3}$ Lei n. 9.504/1997, art. 73, V, caput.

${ }^{4}$ Lei n. 9.504/1997, art. 73, V, “d”.
} 


\section{Introdução - ementas das decisões sob análise}

Como dito, a diretriz jurisprudencial estabelecida na instância superior eleitoral é excessivamente restritiva, no que se refere à contratação temporária pela Administração em anos eleitorais, pois considera serviço público essencial somente aquele de natureza emergencial, "umbilicalmente ligado à sobrevivência, à saúde ou à segurança da população”, a teor da ementa do acórdão paradigma ${ }^{3}$, a seguir transcrita:

CONDUTA VEDADA A AGENTE PÚBLICO EM CAMPANHA ELEITORAL. ART. 73, INCISO V, ALÍNEA “D”, DA LEI № 9.504/97.

1. Contratação temporária, pela Administração Pública, de professores e demais profissionais da área da educação, motoristas, faxineiros e merendeiras, no período vedado pela lei eleitoral.

2. No caso da alínea "d" do inciso V da Lei no 9.504/97, só escapa da ilicitude a contratação de pessoal necessária ao funcionamento inadiável de serviços públicos essenciais.

3. Em sentido amplo, todo serviço público é essencial ao interesse da coletividade. Já em sentido estrito, essencial é o serviço público emergencial, assim entendido aquele umbilicalmente vinculado à "sobrevivência, saúde ou segurança da população".

4. A ressalva da alínea "d" do inciso V do art. 73 da Lei $n^{\circ}$ 9.504/97 só pode ser coerentemente entendida a partir de uma visão estrita da essencialidade do serviço público. Do contrário, restaria inócua a finalidade da lei eleitoral ao vedar certas condutas aos agentes públicos, tendentes a afetar a igualdade de competição no pleito. Daqui resulta não ser a educação um serviço público essencial. Sua eventual descontinuidade, em dado momento, embora acarrete evidentes prejuízos à sociedade, é de ser oportunamente recomposta. Isso por inexistência de dano irreparável à "sobrevivência, saúde ou segurança da população".

5. Modo de ver as coisas que não faz tábula rasa dos deveres constitucionalmente impostos ao Estado quanto ao desempenho da atividade educacional como um direito de todos. Não cabe, a pretexto do cumprimento da obrigação constitucional de prestação "do serviço", autorizar contratação exatamente no período crítico do processo eleitoral. A impossibilidade de efetuar contratação de pessoa em quadra eleitoral não obsta o poder público de ofertar, como constitucionalmente fixado, o serviço da educação".

${ }^{3}$ TSE. Recurso Especial Eleitoral n. 27.563. Relator Ministro Ayres Britto, DJ 12 de fev. de 2007. 
Por conta dessa interpretação, a Corte Superior Eleitoral tem reprimido todo ajuste provisório firmado no ano da eleição pela Administração para admissão de profissionais na área da educação, sob o fundamento de que não prestam serviço público de natureza essencial.

Nas eleições municipais de 2016, o Tribunal Regional Eleitoral de Santa Catarina adotou posição diametralmente oposta, ao reconhecer a legitimidade de semelhante conduta, desde que comprovada a sua imprescindibilidade para dar continuidade à prestação dos serviços, consoante revela a ementa do referido precedente ${ }^{4}$ :

- ELEIÇÕES 2016 - RECURSOS - AÇÃO DE INVESTIGAÇÃO JUDICIAL ELEITORAL (AIJE) - SENTENÇA CONDENATÓRIA COM APLICAÇÃO DE PENALIDADE PECUNIÁRIA PELA PRÁTICA DE CONDUTA VEDADA AOS AGENTES PÚBLICOS DURANTE A CAMPANHA ELEITORAL (LEI N. 9.504/1997, ART. 73, V).

- PRELIMINARES REJEITADAS: (1) INÉPCIA DA INICIAL PEÇA ACUSATÓRIA DESCREVENDO DIVERSOS ATOS ADMINISTRATIVOS MUNICIPAIS QUE PODERIAM, EM TESE, CONFIGURAR O COMETIMENTO DE ILÍCITOS ELEITORAIS DE RESPONSABILIDADE COMUM, DA COLIGAÇÃO E DOS CANDIDATOS DEMANDADOS - ARGUMENTAÇÃO FÁTICA E JURÍDICA APTA A TORNAR VIÁVEL O PLENO EXERCÍCIO DA DEFESA E DO CONTRADITÓRIO. (2) ILEGITIMIDADE PASSIVA DA COLIGAÇÃO E DO CANDIDATO AO CARGO DE VICE-PREFEITO - POSSIBILIDADE LEGAL DE IMPOR REPRIMENDA AOS ELEITORALMENTE BENEFICIADOS PELA PRÁTICA DAS CONDUTAS ILÍCITAS PREVISTAS PELO ART. 73, SS 4ํㅡ E 8 DA LEI N. 9.504/1997. - MÉRITO: HIPÓTESE RECURSAL CIRCUNSCRITA À DISCUSSÃO DAS CONTRATAÇÕES TEMPORÁRIAS REALIZADAS DURANTE O ANO ELEITORAL PELA GESTÃO DO PREFEITO, CANDIDATO À REELEIÇÃO - CONTRATAÇÕES TEMPORÁRIAS ENVOLVENDO 141 PESSOAS, PROFISSIONAIS DAS ÁREAS DA SAÚDE E DA EDUCAÇÃO - EXAME DAS ADMISSÕES E DE SUA ESSENCIALIDADE PARA A CONTINUIDADE DO SERVIÇO PÚBLICO A AUTORIZAR O ENQUADRAMENTO NAS EXCEÇÕES LEGAIS

${ }^{4}$ TRESC. Acórdão n. 33.001. Relator Juiz César Augusto Mimoso Ruiz Abreu. DJe de 23 de jul. de 2018. 
DO ART. 73, V, “D”, DA LEI N. 9.504/1997 - SINGULARIDADES DO CASO CONCRETO:

(1) ADMISSÃO EMERGENCIAL DE 40 PROFISSIONAIS DA SAÚDE AUTORIZADA POR LEI COMPLEMENTAR APROVADA PELA CÂMARA DE VEREADORES E REALIZADA PARA VIABILIZAR A PRESTAÇÃO DE SERVIÇOS EM UNIDADE DE PRONTO ATENDIMENTO, BEM COMO SUPRIR O AUMENTO DE DEMANDA DE TRABALHO EM LOCAIS ESPECÍFICOS E SUBSTITUIR SERVIDORES EXONERADOS. (2) EMPREGO DE 89 PROFISSIONAIS, POR TEMPO DETERMINADO, NA ÁREA DA EDUCAÇÃO PARA O FIM DE SUBSTITUIR SERVIDORES EFETIVOS AFASTADOS EM RAZÃO DO GOZO DE LICENÇAS AUTORIZADAS POR LEI, PARA ATENDER O AUMENTO INESPERADO DE DEMANDA E CARÊNCIAS ESPECÍFICAS DE ALUNOS ESPECIAIS.

(3) CONTRATAÇÃO TEMPORÁRIA DURANTE O PERÍODO ELEITORAL DE 12 PROFISSIONAIS DA SAÚDE E TAMBÉM DA EDUCAÇÃO PARA SUBSTITUIR SERVIDORES COM CONTRATO DE TRABALHO ENCERRADO - CASOS EM QUE ERA POSSÍVEL PREVER O TÉRMINO DA RELAÇÃO CONTRATUAL.

- COMPROVAÇÃO DE QUE A MAIORIA DAS CONTRATAÇÕES OBJETIVARAM GARANTIR A FORÇA DE TRABALHO NECESSÁRIA AO FUNCIONAMENTO DOS SERVIÇOS PRESTADOS NAS ÁREAS DA SAÚDE E DA EDUCAÇÃO, CONSIDERADAS ESSENCIAIS, INDISTINTAMENTE. INEQUÍVOCA PRESENÇA DOS REQUISITOS DA ESSENCIALIDADE DO SERVIÇO PÚBLICO E DA IMPREVISIBILIDADE DA ESMAGADORA MAIORIA DAS CONTRATAÇÕES, A JUSTIFICAR A EXCEPCIONALIDADE DE QUE TRATA O ART. 73, V, “D”, DA LEI N. 9.504/1997.

- INOBSERVÂNCIA DO REQUISITO DA IMPREVISIBILIDADE EM CONTRATAÇÕES RESIDUAIS QUE, EMBORA NÃO AFASTE A VIOLAÇÃO DA NORMA PROIBITIVA, NÃO REVELA ILÍCITO COM GRAVIDADE SUFICIENTE PARA AFETAR A REGULARIDADE E A LEGITIMIDADE DO PLEITO ELEITORAL. IMPOSIÇÃO DE PENALIDADE PECUNIÁRIA QUE SE JUSTIFICA PARA O CASO CONCRETO.

- DESPROVIMENTO DO RECURSO DA COLIGAÇÃO REPRESENTANTE E PROVIMENTO PARCIAL DO APELO DOS REPRESENTADOS APENAS PARA DIMINUIR O VALOR DA 
MULTA APLICADA - RESPONSABILIZAÇÃO SOLIDÁRIA ENTRE OS REPRESENTADOS PELO ADIMPLEMENTO DA PENALIDADE PECUNIÁRIA.

Em outro julgado, também referente ao pleito de 2016, a Corte catarinense considerou igualmente lícita a contratação realizada no ano eleitoral para a execução de serviços na rede municipal de ensino de forma transitória 5 .

\section{Fundamentos fáticos e jurídicos do posicionamento adotado pelo TRESC. Adoção de parâmetros constitucionais respeitantes aos serviços públicos essenciais. Observância da jurisprudência firmada pelo STJ e STF}

Na controvérsia dirimida pelo Tribunal Regional Eleitoral, a chefia do Poder Executivo municipal foi acusada da prática de conduta vedada por conta da contratação, no decorrer do ano de 2016, de 42 servidores temporários na área da saúde e outros 99 na da educação, sem a suposta comprovação do excepcional interesse público.

$\mathrm{Na}$ sentença, o Juiz Eleitoral reconheceu a essencialidade e a imprevisibilidade dos ajustes administrativos firmados para atender a demanda de pessoal na área da saúde, mas concluiu pela ilicitude das contratações temporárias para fins educacionais, na linha da orientação jurisprudencial do Tribunal Superior Eleitoral, o que motivou a imposição de multa pecuniária aos representados.

Em grau recursal, contudo, o Pleno do Tribunal Regional Eleitoral de Santa Catarina concluiu que a prestação de serviços públicos na área da educação também deveria ser considerada de natureza essencial e, por conseguinte, justificar a incidência da exceção legal em análise.

Ao defender esse posicionamento, o Relator consignou que " $\mathrm{O}$ legislador constituinte conferiu à educação o mesmo status reservado à segurança pública e à saúde, ao afirmar, de forma expressa, que representam direitos de todos e dever do Estado (arts. 144 e 205, ambos da CF)".

\footnotetext{
${ }^{5}$ TRESC. Acórdão n. 32786. Relatora Juíza Luísa Hickel Gamba. DJE de 16 de out. de 2017.
} 
Para corroborar essa afirmação, foram indicados precedentes do Superior Tribunal de Justiça ${ }^{6}$ e do Supremo Tribunal Federal ${ }^{7}$, nos quais restou reconhecida a essencialidade dos serviços prestados pela Administração na concretização do direito constitucional à educação.

Também foram apontados julgados do Tribunal de Justiça de Santa Catarina afirmando que a prestação de serviços públicos em referida área está abarcada entre os direitos compreendidos no conceito do "mínimo existencial" a ser assegurado pelo Estado a todo cidadão, em respeito ao princípio da dignidade da pessoa humana ${ }^{8}$.

No que se refere ao requisito da inadiabilidade da contratação temporária, o Relator adotou como elemento distintivo o conceito de imprevisibilidade, o qual, nas suas palavras, "deve ser entendido como a comprovação da ocorrência de contingência, de caráter transitório, que não poderia ser prevista pelo gestor público".

Em razão disso - e somente por essa razão -, algumas das admissões temporárias foram consideradas ilícitas pelo Relator, pois as situações fáticas invocadas para justificá-las não demonstravam a necessidade premente e inadiável exigida para a incidência da ressalva legal.

Como consequência, o recurso foi parcialmente provido para reduzir a multa aplicada, já que a grande maioria das contratações realizadas na área da educação, incialmente consideradas ilícitas pelo Juiz Eleitoral, acabaram sendo admitidas como legítimas pelo Tribunal.

Embora nesse ponto específico, os Juízes da Corte Regional tenham discordado quanto à imprescindibilidade de algumas contratações temporárias, as divergências foram bastante pontuais, decorrentes das peculiaridades do caso concreto, mais precisamente quanto aos motivos invocados pela gestão municipal em determinadas situações.

Ao final, o entendimento firmado, de forma unânime, foi o de que os serviços públicos relacionados à área da educação são essenciais e, por essa razão, admitem a contratação temporária no ano da eleição, sempre que comprovada a sua necessidade inadiável.

\footnotetext{
${ }^{6}$ STJ. Recurso Especial n. 104.1197/MS. Relator Ministro Humberto Martins. DJe de 16 de set. de 2009.

${ }^{7}$ STF. Ação Direta de Inconstitucionalidade n. 3247. Relatora Ministra Cármen Lúcia. DJe de 26 de mar. de 2014.

8 TJSC. Apelação Cível n. 0800654-36.2013.8.24.0007, Relator Desembargador Newton Trisotto, de 28-09-2017; Agravo de Instrumento n. 0128122-66.2015.8.24.0000, Relator Desembargador Paulo Henrique Moritz Martins da Silva, de 16-05-2017.
} 


\section{Considerações finais}

Não há como negar a plausibilidade jurídica da interpretação mais elástica adotada pelo Tribunal Regional Eleitoral de Santa Catarina quanto à amplitude do conceito de serviço público essencial para fins de incidência da regra de exceção em comento.

O reconhecimento da essencialidade do direito à educação não afronta o interesse público de preservação da lisura do pleito, nem desvirtua a finalidade da lei eleitoral. Ao revés, reforça a legitimidade das restrições impostas pela lei aos agentes públicos durante o período de campanha, porquanto permite a convivência harmônica de primados jurídicos de igual grandeza constitucional, sem prejudicar o acesso da população a direitos fundamentais.

Num contexto em que severas restrições orçamentárias impedem os entes federativos de recompor seu quadro de pessoal, agravado pelo incessante aumento da população, impedir a contratação temporária de profissionais na área da educação no ano da eleição, mesmo em situação comprovadamente emergencial, pode colocar em risco - senão paralisar - o atendimento gratuito prestado à sociedade nos estabelecimentos de ensino da rede pública.

Esse quadro mostra-se ainda mais alarmante se considerarmos que o Brasil tem 14 milhões de analfabetos, possuindo a oitava maior população de adultos analfabetos do mundo, a frente apenas de países como Paquistão, Nigéria ou Etiópia e atrás de Indonésia e Congo9.

Ao deixar de considerar a educação como serviço essencial, a Justiça Eleitoral corre o risco de acabar desencorajando gestores públicos a investirem recursos nessa importante área, pelo simples receio de sofrerem reprimendas, agravando ainda mais os graves problemas sociais que a afligem.

Por isso mesmo, a coragem do Pleno do Tribunal Regional Eleitoral de Santa Catarina em contrapor o entendimento sedimentado pela instância superior é louvável, especialmente porque tem o condão de incitar a rediscussão jurisprudencial dessa importante matéria.

\footnotetext{
${ }^{9}$ Reportagem da Revista Veja sobre o "Relatório de Monitoramento Global da Educação 2017/8" divulgado pela Organização das Nações Unidas para a Educação, a Ciência e a Cultura (Unesco). Disponível no endereço eletrônico: <https://veja.abril.com.br/blog/ impavido-colosso/brasil-e-o-8-pais-com-mais-adultos-analfabetos-do-mundo/>
}

Resenha Eleitoral (Florianópolis), v. 22, n. 1-2, p. 231-238, 2018 
Contudo, é preciso alertar que a Corte Superior Eleitoral já deu sinais de que não irá rever o seu posicionamento, ao menos, nesse momento.

Posteriormente à publicação do acórdão regional em análise, os Ministros da Corte Superior, de forma unânime, reafirmaram o entendimento de que "admissões de docentes não se enquadram na ressalva da alínea 'd' do inciso V da Lei 9.504/97, por não integrarem serviço público essencial, pois, ainda que a descontinuidade da educação acarrete prejuízos, não haverá dano irreparável à 'sobrevivência, saúde ou segurança da população" $" 10$.

Mais recentemente, foi proferida decisão monocrática dando parcial provimento ao recurso especial interposto pela Procuradoria Regional Eleitoral contra a decisão colegiada do Tribunal catarinense em análise, a fim de majorar a multa imposta aos recorridos, sob o argumento de que "a contratação temporária para a área de educação não caracteriza a inescusável premência a que alude a multicitada alínea 'd' do inciso $\mathrm{V}$ do art. $73 \mathrm{da}$ Lei $9.504 / 97 " 11$.

Embora mencionada decisão possa ser reformada no julgamento em Plenário, a prudência recomenda que os agentes públicos, durante o ano eleitoral de 2020, não realizem quaisquer contratações temporárias na área da educação em âmbito municipal, sob pena de serem demandados judicialmente e estarem sujeitos à imposição das penas de multa, bem como de cassação de mandato eletivo.

Marcus Cléo Garcia - Servidor público efetivo do Quadro Permanente do Tribunal Regional Eleitoral de Santa Catarina, onde exerce a função de Assessor Jurídico da Vice-Presidência; Bacharel em Direito pela Universidade Federal de Santa Catarina (UFSC) e Pós-graduado em Direito Eleitoral pela Universidade do Vale do Itajaí.

\footnotetext{
${ }^{10}$ TSE. Agravo Regimental em Recurso Especial Eleitoral n. 461-66. Relator Ministro Jorge Mussi. DJe de 29 de ago. de 2018.

11 TSE. Recurso Especial n. 425-21. Relator Ministro Jorge Mussi. Decisão monocrática disponibilizada no DJe de 09 de maio de 2019.
} 